extract was dried with solid potassium hydroxide, filtered and evaporated. On fractionating the residue, furanethylamine distilled at $155^{\circ}$ under atmospheric pressure. It readily absorbed carbon dioxide and converted into the carbaminate which formed white crystals, melted at $86-87^{\circ}$. The yield was not good. The picrolonate was prepared from the carbaminate by adding an aqueous solution of picrolonic acid. It was crystallized from hot water in yellow prisms and decomposed at $203^{\circ}$. (Found: $\mathrm{N}=18.43 \quad \mathrm{C}_{6} \mathrm{H}_{9} \mathrm{NO} \cdot \mathrm{C}_{10} \mathrm{H}_{8}$ $\mathrm{N}_{4} \mathrm{O}_{5}$ requires $\mathrm{N}=18.64$ per cent.)

\title{
BIBIJIOGRAPHY.
}

1) Windaus and Dalmer: Ber., 53, 2304, 1920.

2) Asahina and Fujita: J. Pharm. Sor. Japan, 490, 1081, 1922.

3) I. Bcuveault and A. Wahl: Comp. rend, 135, 41, 1902; Bull, Soc. Chim. (3) 29. 521, 1903.

4) Gabriel: Ber., 18. $2438,1885$.

\section{STUDIES ON IMIDAZOL DERIVATIVES.}

\section{PART I. PREPARATION OF 4 (5)-METHYLGLYOXALINE.}

\author{
$\mathrm{By}$ \\ Teijiro Yabuta and Katsuji Kambe. \\ (Agricultural Chomical Laboratory, Facully of Ayriculture, Tokyo Imperial University.)
}

(Received March 31st., 1928)

The preparation of $4(5)$-methylglyoxaline by the method of Windaus and Knoop has been modified in the following manner, so that instead of allowing to stand the reaction mixture at room temperature for several weeks it is heated in water bath at $50--60^{\circ}$ for two days, and the purification is carried out by direct distillation of the raw product in a vacuum, the object in view being the simplification of the procedure for the preparation of methylglyoxaline in a large amount.

Zink hydroxide was prepared by adding 425 c.c. of $28 \%$ ammonia to the solution of $1 \mathrm{~kg}$. of crystalline zink sulphate (corresponds to $563 \mathrm{~g}$. of anhydrous substance) dissolved in $8 \mathrm{I}$. of water. It was at first washed with water by decantation and then on Buchner's funnel until free of sulphate. The zink hydroxide, after well drained, was dissolved in 2L. of $28 \%$ ammonia. $1.35 \mathrm{~kg}$. of commercial crude glucose (containing $74 \%$ of anhydrous glucose, 
correspond to $1 \mathrm{~kg}$. of pure substance) was dissolved in it.

The solution was placed in a pressure bottle and heated in a water bath at $50-60^{\circ}$ The reaction was found to be complete about in two days, since no more precipitate separated from the supernatant solution set apart.

The precipitate was filtered by suction and drained on porous plate yielding $320 \mathrm{~g}$. It was now suspended in warm water and hydrogen sulphide gas was passed to it. The filtrate together with the washing water from the zinc sulphide were evapolated under diminished pressure. On fractionating the residue, methylglyoxaline distilled at $144-146 / 4 \mathrm{~mm}$. yielding $120 \mathrm{~g}$.

The picrate was prepared and analysed; (found: $\mathrm{N}=22.63 \mathrm{C}_{4} \mathrm{H}_{6} \mathrm{~N}_{2} \cdot \mathrm{C}_{6} \mathrm{H}_{3}$ $\mathrm{N}_{3} \mathrm{O}_{7}$ requires $\mathrm{N}=22.51$ per cent.) The nitrate melted at $115^{\circ}$. and the hydrochloride was extremely hygroscopic plates.

\title{
Bibriograpiy.
}

(1) Hoppe Seyler: Ber., 4, 346 (1871).

(2) Shützenberger: Bull. Soc. Chim, 2 25, 289

(3) Nencki und Sieber: Juurn. fuir prakt. Chem., 2 24, 498 (1881).

(4) Windaus und Knoop: Ber., 38, 1166 (1905).

(5) Pinkus: Ber., 31, 32 (1898).

(6) J. V. Nef: Ann. d. Chem, 335, 254, 279 (1904).

(7) Wohl: Lippmann, Chemie der Zuckerarten, (1904) 1891

(8) Buchner: Ber., 38, 621 (1905).

(9) Gabriel und Pinkus: Ber., 26, 2205 (1893).

(10) Jowett und Potter: Journ. Chem. Soc., 83, 464

(11) Windaus: Ber., 39, 3886 (1906).

\section{STUDIES OF GERMINATION OF SEEDS. PART I.}

\author{
TRANSFORMATION OF NITROGENOUS COMPOUNDS \\ DURING GERMINATION OF SOYA-BEAN SEEDS.
}

By

\author{
SHUIKU SASAki. \\ (From the Biochemical Laboralory, Department of \\ Agrieulure Kyushu Imperial Unizersily.) \\ (Received Apr. 1st., 1928)
}

The present paper consists of two parts ; that is, "Method of Germination" and "Analysis of nitrogenous compounds in seeds and seedlings". 